\title{
Effects of Solution - Focused Group Counseling on Student's Self - Regulation and academic achievement
}

\author{
Rooholla Saadatzaade and Shiva Khalili \\ University of Tehran, Iran
}

\begin{abstract}
The purpose of this study was to explore the effectiveness of solution -focused counseling on selfregulation and academic achievement of high school students. Solution-focused counseling was evaluated through control and experimental pretest - posttest group design. After seven sessions group counseling with students, the self-regulation and academic achievement of students in the counseling intervention group were significantly increased. Moreover, the findings indicated significant difference between control group and experimental group in post test results $(p<0 / 05)$.
\end{abstract}

\section{Introduction}

Contemporary school counselors have the duty to support the academic, vocational, individual and social development of all students [7]. New vision school counseling requires a belief in the capacity of all students to obtain high levels of academic achievement and meaningful futures in a global economy and technologically advanced world. New vision school counselors engage in systemic leadership, advocacy, collaboration, counseling, coordination, assessment, and data analysis. Serving as social action agents, new vision school counselors identify and remove inequities and other barriers to academic achievement.

Solution-focused counseling is an efficient and direct approach that emphasizes problem identification and solutions. Practitioners following a solution-focused approach focus on student skills and solutions rather than deficits and problems. This positive emphasis appears well-suited for students who possess sufficient academic skills but lack the motivation, confidence, and perseverance needed to be successful. The professional school counselor is a certified/licensed educator trained in school counseling with unique qualifications and skills to address all students' academic, personal/social, and career development needs. Professional school counselors implement a comprehensive school counseling program that promotes and enhances student achievement. Professional school counselors are employed in elementary, middle/junior high, and high schools and in district supervisory, counselor education, and post-secondary settings. Their work is differentiated by attention to developmental stages of student growth, including the needs, tasks, and student interests related to those stages.

\section{Solution-focused counseling}

Solution-focused therapy was developed by Steve de Shazer and his colleagues at the Brief Family Therapy Center (BFTC) in Milwaukee, Wisconsin. Solution-focused therapy was influenced by the Mental Research Institute's (MRI) problem-focused therapy (e.g., Fisch, Weakland, and Segal, [11]) in Palo Alto, California.

In problem-focused therapy, problems are conceptualized as repeated applications of ineffective solution attempts. It follows that in problem-focused therapy," the solution is the problem." In contrast, solution-focused therapy developed an inverse of the problem/solution ascription by proposing that the problem has within it the seeds of a solution.

\subsection{Solution-Focused Techniques}

2.1.1. Mapping the Influences of the Problem: Michael White, in his narrative therapy model [25], developed a technique called mapping the influences of the problem, which can be adapted within solution-focused counseling. In narrative therapy, this technique refers to a line of questioning aimed at helping the client understand how the problem has influenced his or her life. This process serves to increase opportunities for identifying unique outcomes (a phenomenon that is similar to exceptions). When mapping the influences of the problem, counselors ask how the problem has affected various aspects of the client's life, including relationships, work, and daily functioning.

Mapping the influences of the problem is a way to speak to some clients' need to talk about the problem, address its influences, and feel as if the problem is not being stolen away from them. This is one of the down sides of a solution-focused approach and brief counseling models in general. Because brief counseling models are designed to produce such rapid results, some clients are left feeling as if the treatment is superficial. Mapping the influences of 
the problem can address such concerns. If the problem is depression, then the counselor might ask the client to identify ways in which depression has affected aspects of their life.

The counselor might ask, "How has the depression affected your work?," "How has the depression affected your relationships with family members?," or "How has the depression affected your health?"

A second purpose of this technique in solutionfocused counseling is to use the influences as a basis from which to later identify exceptions. After the client has identified various influences of the problem, the counselor can go back to these influences and inquire about exceptions. In the case of anger, for example, the counselor might inquire about exceptions at work, in the client's relationships with family members, and with regard to his or her health.

Many times clients understand the problem as an on/off experience [9]. You either have it or you don't. Scaling techniques are useful for clients who find it difficult to discern exceptions and notice differences. Scales are useful because we can bypass the limitations of language and agree upon a term for example, “6," “9,” or “2”- to denote what would otherwise be a subjective experience. Ask clients to rate their subjective experiences, such as how they feel, how they deal with their problems, and so forth on a scale from 0 to 10 . Molnar and de Shazer [19] developed a reverse scale which can be effective: The rating scale was deliberately upside-down. This was designed to help confuse the up-down metaphor and to have the shift from "depressed" (i.e., 7 or 8 ratings) to "normal" (2 or 1 ratings) be represented by a "downhill slide" rather than an "uphill battle." (p. 352)

Ask clients to keep a written record to keep track of their ratings. For example, for a client with anxiety, ask them to rate the severity of their anxiety on a daily basis. In addition, ask them to record other information, such as what happened, what they did to cope, who they spent time with, and so forth. Then, review the ratings with your client, and focus on the client's best days and highlight the other information that was recorded as these are exceptions that can be amplified.

The structured log or journal is a useful exercise for clients who are unable to identify exceptions, are only able to identify potential exceptions, are not focused, are only able to construct vague goals, or are not able to develop goals at all. The client might be asked to keep track of times when the problem does not happen or when the goal happens. The client is asked to describe in detail what they did, how they coped, what was different, and so forth. For example, if a client describes the goal of counseling as, "I want to be more in control of my life,” they might be asked to keep a log of what they are doing when they find that they are feeling more in control of their life. Recalling that small changes can lead to big results, the client should be asked to make notes of any small examples, too. The structured log often leads to helping the client identify exceptions and set more attainable and realistic goals.

2.1.2. What's Better?: De Shazer [9] proposed a simple question that counselors can use during follow-up sessions aimed at identifying exceptions: "What's better?" This is a good question to ask if you are unclear regarding where you left off after the prior session. Perhaps you did not agree on a task. Maybe it was unclear what the task would be. Maybe you and the client were unsure of what direction you were going in at the end of the prior session. Starting off the next session with the question, "What's better?" can get you and the client in a solutionfocused direction from the start. This question might also help identify exceptions that were missed in prior sessions or raise new problems and exceptions that were never discussed before in counseling. There are many variations to the "What's better?" question. You can ask the client, "What's new?" You can even start the session with more neutral questions by asking, "What's up?" or "What do you want to talk about?”

\subsection{The special strategies of solution- focused counseling:}

1. The real pry.

2. Speaking in client language.

3. Embossing abilities and potentials.

4. Commending client.

5. Considering changes.

6. Focused on here and now.

7. Instructing optimize.

8. Looking for exceptions to the problem.

9. Miraculous question.

10. Qualifying the accurate, accessible, and measurable goals.

11. Codifying and adjusting the purpose more accurately.

12. Assigning homework tasks;

13. Looking for strengths or solutions;

14. Goal-setting;

\section{Self-regulation}

In the research literature, much has been written about how best to define self-regulation. There is consensus among researchers that self-regulation involves a cognitive direction that requires continuous adaptations and decisions, awareness to gain intelligent and valid comprehension of each situation, and a reflective disposition about what 
should be done, is being done, or has been done in the various academic activities and in life in general. The importance of self-awareness during the task, monitoring one's progress while performing it and finding new strategies when the previous ones did not lead to successful task completion are central to self-regulatory activities.

In recent years self-regulation increasingly has been applied to learning settings involving academic studying and other forms of learning (e.g., cognitive, motor, social skills) [3]. A large part of the rationale for studying academic self-regulation came from research showing that learners' skills and abilities did not fully explain their achievement [26], which suggests that other factors such as motivation and self-regulation were important. Applying selfregulation to education also broadened its scope to actual learning beyond the historical emphasis of performance of previously learned actions. Today several theoretical perspectives exist to guide selfregulation research [26], and self-regulation is viewed as a process that can help explain achievement differences among students and improve their achievement [3].

The self-regulation process involves three phases - forethought, performance, and evaluationthat the student applies repeatedly during learning. The aim of forethought is to guide both the mind and the performance in any specific task, and to plan future actions. Performance consists of the execution of the activity, controlling not only every aspect involved in the development of the activity, but also those factors that may affect specification and distribution of time and effort. Evaluation refers to the phase subsequent to the learning effort; that is, the analysis of whatever occurred, the results obtained, and the relationship between that particular activity and other similar ones. When the cycle ends another behaviour-regulation process begins. According to Brown and Palincsar (1989) and other authors, self-regulation improves with age. However, the acquisition of this skill is not necessarily associated with natural development. Therefore, as with any other capacity or content, it should be explicitly taught.

\subsection{Goals and self-regulation}

Conceptualizations about the relations of goals and behavior regulation have followed two distinctive tendencies. The first concentrated on different goal-orientations. The second focused on goal setting.

3.1.1. Goal-orientations and self-regulatory processes: Learning and performance goals are the two main goal-orientations described in achievement contexts. Under a learning goal, individuals strive to improve their competence. Under a performance goal, individuals seek to demonstrate high ability. Each goal-orientation creates different patterns of motivation that are relevant to regulatory processes. More specifically, learning goals and performance goals are associated, respectively, with (1) effort versus ability attributions (that provide a different basis from which to monitor goal progress and to plan future behavior), and (b) the utilization of metacognitive strategies and self-monitoring versus effort avoidance and strategy deterioration.

Of particular importance is that students who pursue a learning goal value learning itself and rely on effort to attain that goal. Their goal orientation is conducive to self-regulated behavior in the academic domain. In contrast, students who pursue performance goals value normative ability standards and avoid effort utilization.

Attention is focused on the evaluation of one's ability and directed away from the requirements of the task. This goal orientation makes self-regulation more difficult.

Monitoring goal progress (demonstrating higher ability than others) is also more complex, since it depends in part on imponderable factors, such as the performance of others, and the validation of one's ability by others, further hindering self-regulation.

3.1.2. Goal-setting and self-regulation: Goals play two major functions in the regulation of behavior. One is a directing function (where goals are endstates required for planning and strategy utilization). The second is a monitoring function (where goals are standards or criteria for evaluating behavior). Selfregulated behavior is a particular form of behavior regulation in which goals are established or valued by the individual himself or herself, thus allowing the self-management of both goal functions. Goalsetting, goal valuing, self-goals, and personal goals will be used as equivalent terms, denoting the essential prerequisite of the goals that are conducive to self-regulated behavior.

Major conceptions of self-regulation explicitly or implicitly stress personal goal valuing. Selfregulation implies a systematic orientation toward the attainment of one's goals [26]. Self-regulation relies on personal representations of standards and requires discrepancy production, i.e., personal goalsetting [1]. Self-regulation is a deliberative process in which individual goal-setting is central [6]. Selfregulation derives from the personal attachment to a goal [17].

While diverse models acknowledge the importance of personal goals for self-regulation, some most directly and extensively focus on how behavior becomes self-regulated. Within the motivational literature Nuttin [20], Deci and Ryan [10], and Harter [14], [15] have outlined internalization processes conducive to selfregulation, in which personal goals related constructs 
play a pivotal role. Nuttin [20], for example, describes the process of "personalization of motivation", the main result of which is the internal regulation of behavior. According to Nuttin, the behavioral process begins with the construction of the standard (goal) itself. Goals are the product of the cognitive transformation of behaviorally undetermined needs into something specific to be achieved. This process results in the personalization of motives and in self-regulation 'since goals are personal constructs and standards given by the subject to himself as criteria for self-evaluation (p. 144). Reaching one's goals becomes a "personal affair" (p. 179) and the individual engages in behaviors leading to the goal as a personal project, taking the initiative and responsibility for its accomplishment.

The cognitive elaboration of needs also involves the construction of a plan to achieve the goal. Plans are means-end structures in which means are contingently related to each other and to the final goal. These connections also facilitate selfregulation, namely allowing the delay of immediate gratification for the sake of more important later forms of gratification, and protecting intentions against easier and more attractive available alternatives [20].

According to Deci and Ryan [10], the development of self-regulation capacities is rooted in the internalization of values, incentives, and interests within the self. Internalization refers to the processes through which someone can become more autonomous in performing an activity that was initially externally prompted. To be autonomous means to be self-initiating and self-regulating (p. 621). In addition to intrinsic motivation the authors define three other regulatory styles - extrinsic, introjected, and identified representing different types of internalization which reflect progressively higher degrees of autonomy. External regulation refers to behavior regulated by the anticipation of extrinsic contingencies. Introjected regulation refers to behavior guided by internal but not fully accepted reasons. Within this style, regulation results from internal pressures to behave in certain ways, through contingent self-rewarding or punishing based on performing one's duties or on guilt.

Identified regulation describes self-regulated behavior, that is, behavior governed by one's own values or goals.

Within Harter's model [14], [15], the child progressively develops a self-reward system, transforming previously extrinsically regulated behavior into internalized behavior regulation. This includes interest rather than anticipation of reward as the incentive of engagement, personal efficacy rather than extrinsic approval as the origin of satisfaction, and self-definition of goals and of criteria of goal- attainment rather than orientation towards modeled goals and reliance on externally provided feedback. To some degree, all these models stress goal valuing and personal commitment to reach goals as essential to self-regulation. Common to these views is the notion that internalization is the process by which the individual personally invests in goal pursuit and, as a consequence, becomes increasingly self-regulated. The consideration of personal goal valuing widened the range of internal forms of regulation. These forms support engagement in activities that are not intrinsically interesting, by linking them to the achievement of personal goals. This adds new pathways to good learning and developmental results, increasing the probability of bringing them about.

Commonalties are also apparent in that the core features of non-optimal forms of regulation involve particular failures in personal goal valuing and planning. For example, "introjected regulation" resembles Nuttin's "motivational alienation", both describing instances in which individuals do or wish for things that are inconsistent with their own intentions. Behavior associated with these patterns of regulation is over-controlled, rigid, and alienated. "motivational" and "external" regulations reflect "failures to internalize significant values, impairing the capacity to modulate one's urges.

These concepts are convergent with Nuttin's definition of 'helplessness, which describes the inability to transform a need into a concrete goal, thus hindering the ability to tolerate the frustration of delayed gratification [20].

In summary, these models reveal complementary and convergent conceptualizations that contribute to a shared understanding of the foundations of selfregulation.

Such conceptualizations can be summarized under the notion of internalization of goal-related constructs (e.g., values, rewards, and incentives) within the self.

Effective self-regulation is the bedrock of healthy psychological functioning. People who routinely are successful at self-regulation benefit from a sense of psychological stability and personal control that allows them to manage their perceptions of themselves and how they are perceived by others. Their behavior typically reflects salient goals and adopted standards of behavior. Departures from these desired states are handled smoothly and effectively. People who routinely fail at self-regulation enjoy none of the psychological benefits that derive from a sense of psychological stability and control and struggle with mild to severe forms of psychopathology. Effective self-regulation, by which people control their thoughts, feelings, and behaviors, is essential for adaptive functioning. 


\section{Academic Motivation}

Motivation has been defined by social cognitive researchers as a process in which goal-directed behavior is instigated and sustained.

It is an important variable because it has been consistently associated with academic competence and is often the subject of teacher concerns about students struggling in school. Motivation can manifest itself in various forms such as effort, persistence, and choice of activities-indexes that are hypothesized to be influenced by students' selfefficacy. This hypothesis has been consistently confirmed by researchers over the past few decades.

That is, when students believe that they can perform a task in a proficient manner, they will become more engaged in the activity, work harder, and sustain high levels of effort even when obstacles are encountered.

In terms of effort, two measures have typically been employed in research: rate of performance and expenditure of energy. There is supporting evidence for the association between self-efficacy and both indexes. Schunk and his colleagues showed that students' perceived self-efficacy for learning correlates positively with their rate of solution of arithmetic problems. In addition, Salomon [21] examined the relationship between sixth grade students' self-efficacy for learning from text and both mental effort and achievement. The selfefficacy of students who were exposed to the print material was positively associated with mental effort and achievement. That is, as students' confidence in their ability to learn from the print material increased, so did their perceived mental effort to complete the task.

Self-efficacy has also been consistently associated with levels of persistence. When they view a task as difficult, students with higher selfefficacy tend to be more persistent than are students with lower self-efficacy. Zimmerman and Ringle [26] assigned children to either an optimistic or a pessimistic model condition, wherein the children observed an adult attempt the solution of an unsolvable wire puzzle.

The optimistic model expressed confidence about solving the puzzle (e.g., "I am sure I can separate these wires; I just have to keep trying different ways, and then I will find the right one") whereas the pessimistic model expressed concern about solving it (e.g., "I don't think I can separate these wires; I have tried many different ways and nothing seems to work”).

Students in the optimistic condition felt more efficacious about being able to solve a similar puzzle and persisted longer than did students in the pessimistic group during an opportunity to solve the problem. The optimistic students also persisted longer in solving an embedded word problem.
This study demonstrated that vicariously-induced self-efficacy not only enhanced persistence on a similar motoric puzzle but also facilitated transfer in persistence to a verbal puzzle within the same experimental context. In addition to its effects on persistence, self-efficacy has been shown to be predictive of students' choice of activities.

\section{Academic Achievement}

Although student motivation is an important issue, the bottom line often entails improving students' academic skills and maximizing their overall performance in school. It is widely accepted that students' academic success is influenced primarily by their cognitive abilities. That is, students with great intellectual potential will often succeed at a higher level than will students with lower ability. However, given that the correlation between IQ and achievement is typically only in the moderate range, it seems reasonable to suggest that cognitive potential does not always translate into attained success. Just as there are intellectually gifted individuals who do not perform well, there exist many lower ability students who perform at or above age or grade expectations. Although it is clear that many variables interact to produce this phenomenon, we will consider the role that self-efficacy perceptions play in determining how well individuals perform academically

This study explains investigating the effect of solution-focused group counseling on self-regulation and academic achievement of high school students.

\section{Method}

\subsection{Participants}

Forty-four male students with low scores in selfregulation and academic achievement were divided in two groups (control and experiment). Participants were first class students from a high school in Tehran that peered in intelligent and mean scores.

\subsection{Design}

The intervention took place during seven week full sessions solution-focused counseling group at a high school in Tehran. Prior to the intervention, participants were administered pre-test in selfregulation and academic achievement (midterm scores). At the end of the intervention, all participants again completed the self-regulation questionnaire and were administered post-test in academic achievement (final scores). 


\subsection{Instruments}

\subsubsection{The Self-regulation Questionnaire (SRQ)}

Building on the foundational work of Frederick Kanfer [16], Miller and Brown formulated a sevenstep model of self-regulation [18]. In this model, behavioral self-regulation may falter because of failure or deficits at these seven steps: 1-Receiving relevant information 2- Evaluating the information and comparing it to norms 3- Triggering change 5Searching for options 4- Formulating a plan 6Implementing the plan 7- Assessing the plan's effectiveness

\subsubsection{Students average grade}

After the midterm exams, the average grades of students were collected and rated as indication for academic achievement of students. The results of students' final exams which took place after the intervention on the experimental group were considered as post test scores for students' academic achievement.

\subsection{Instruction}

A school counselor (Researcher in this study) conducted solution-focused group counseling for experimental group. School counselor and group members worked together for enhancing selfregulation and academic achievement.

Table 1. The summary of seven sessions of intervention

\begin{tabular}{|l|l|}
\hline Session & \multicolumn{1}{|c|}{ Group counseling topic } \\
\hline 1 & $\begin{array}{l}\text { Introducing, group rules, counseling } \\
\text { goals }\end{array}$ \\
\hline 2 & $\begin{array}{l}\text { Formulating positive, accurate, and } \\
\text { measurable goals }\end{array}$ \\
\hline 3 & $\begin{array}{l}\text { Focused on positive exceptions versus } \\
\text { reasons }\end{array}$ \\
\hline 5 & $\begin{array}{l}\text { Help student to change their thought } \\
\text { about academic problems }\end{array}$ \\
\hline 5 & $\begin{array}{l}\text { Focused on here and now, and challenge } \\
\text { thought that "problems always are in } \\
\text { their life and never change" }\end{array}$ \\
\hline 7 & $\begin{array}{l}\text { Focused on miraculous question to } \\
\text { disarrange the behavioral patterns of } \\
\text { student }\end{array}$ \\
\hline $\begin{array}{l}\text { diverse topics, response to student's } \\
\text { questions, supporting students to transfer } \\
\text { skills to outside environment of school }\end{array}$ \\
\hline
\end{tabular}

\subsection{Procedure}

The study utilizes a pretest-post test experimental design. 44 first grade high school male students were assigned in two groups of control and experimental with similar IQ and average academic scores. The experimental group received seven weeks of group counseling session, $80 \mathrm{~min}$. each session, one session per week.

\section{Results}

Table 2. Descriptive statistics (means and standard deviations) of self-regulation and academic achievement

\begin{tabular}{llcccc}
\hline & & \multicolumn{2}{c}{ pretest } & \multicolumn{2}{c}{ Posttest } \\
\hline variable & Group & M & SD & M & SD \\
\hline Self- & Control & 210.6 & 13.9 & 215.2 & 13.8 \\
\cline { 2 - 6 } regulation & Experiment & 207.3 & 15.6 & 240.5 & 11.9 \\
\hline Academic & Control & 9 & 1.30 & 8.9 & 1.7 \\
\cline { 2 - 6 } achievement & Experiment & 8.6 & 1.26 & 10.6 & 1.5 \\
\hline
\end{tabular}

Table 3. Covariance analysis for effectiveness of solution-focused counseling on Academic Achievement and Self-regulation

\begin{tabular}{lcccc}
\hline Variable & $\begin{array}{c}\text { Mean } \\
\text { Square }\end{array}$ & F & P & $\begin{array}{c}\text { Eta } \\
\text { Squared }\end{array}$ \\
\hline $\begin{array}{l}\text { Academic } \\
\text { Achievement }\end{array}$ & 41.18 & 33.30 & 0.000 & 0.49 \\
\hline $\begin{array}{l}\text { Self- } \\
\text { Regulation }\end{array}$ & 7690.22 & 159.60 & 0.000 & 0.79 \\
\hline
\end{tabular}

Table 4. Covariance analysis for effectiveness of solution-focused counseling on Self-regulation subscales

\begin{tabular}{lcccc}
\hline Variable & $\begin{array}{c}\text { Mean } \\
\text { Square }\end{array}$ & $\mathrm{F}$ & $\mathrm{P}$ & $\begin{array}{c}\text { Eta } \\
\text { Squared }\end{array}$ \\
\hline Receiving & 139.31 & 43.21 & 0.000 & 0.51 \\
\hline Evaluating & 91.68 & 17.35 & 0.000 & 0.30 \\
\hline Triggering & 19.32 & 1.50 & 0.22 & 0.035 \\
\hline Searching & 100.10 & 18.91 & 0.000 & 0.31 \\
\hline Formulating & 313.60 & 69.60 & 0.000 & 0.63 \\
\hline Implementing & 232.47 & 30.97 & 0.000 & 0.43 \\
\hline Assessing & 231.82 & 52.28 & 0.000 & 0.56 \\
\hline
\end{tabular}

\section{Discussion}

Learning and implicating goals are two main situations in self regulation that contribute to the concept of development and progress. Selfregulation seems to be a counseling approach with formulation of personal goal in its core [6]. Locke and Latahm [17] define self-regulation as the commitment of a person in reaching her/his goal. 
In this regard it seems that the solution-focused counseling has a meaningful effect on teaching goal formulation, which is a self regulating behavior.

The results of the research indicate that solutionfocused counseling had a significant positive effect on six sub-scales of self regulation (1-Receiving relevant information 2- Evaluating the information and comparing it to norms 3- Searching for options 4- Formulating a plan 5- Implementing the plan 6Assessing the plan's effectiveness). However it didn't show any effect on the seventh subscale "triggering change" between control group and experimental group in post-test.

Initiating change is related to the motivation as well as the evaluation of the resources and the context. According to Adler's theory, goals contribute to the person's motivation.

It was expected that solution focused counseling would increase the motivation of the students, in order to trigger or initiate changes.

The results show however that the students were not motivated to trigger changes in school setting. This might be caused by students' deeply established attitudes and thoughts about school and school assignments.

An explanation for similar situations is offered by Glasser [13], who applies the term "Stacy" for this kind of students. These students have excluded their teachers and school assignments out of their quality world. They usually do not receive any support for education, love and engagement from their families at home. They also do not receive this support at school and are vulnerable to punishment and forced authority at school setting. They show their resistance by excluding school related involvements out of their quality (ideal) world.

This resistance shows itself in the problems of the student to trigger or initiate a change at home or at school. This process of becoming a Stacy starts early at elementary school and comes to a peak at high school [13], and it is very difficult to influence this situation. These students need in depth relationships with patient and kind teachers, representing the only source of love and support for them.

\section{Conclusion}

The results indicate that the solution-focused counseling had a positive influence on the academic achievement. The average scores of control and experimental group showed a significant difference in the post - test. The results support Some's research results [24] on efficacy of solution focused counseling on school attention and academic achievement.

This research is also supporting Franklin et al [12] results showing the positive effect of solution- focused counseling on students' behavioral problems and learning disabilities. The research results show that the effect of solution- focused counseling on self regulation of the students was significant and positive. The intervention emphasized the ability and skills of the students in formulating their goals in positive, measureable and accurate terms.

The results of this research support the studies of Chularut, and De Backer [8], and Sanz et al [22]. However the results of this sample group show that to motivate students to trigger change at school was not affected by the intervention. The authors suggest that changes in student's context and school environment could possibly contribute to this motivation, which will need further investigations.

\section{References}

[1] Bandura, A. (1977). Self-efficacy: Toward a unifying theory of behavior change. Psychological Review, 84, 191215.

[2] Bandura. A. Self-regulation of motivation and action through goal systems. In V. Hamilton, G. H. Bower, \& N. $\mathrm{H}$. Frijda, Cognitive perspectives on emotion and motivation (1987). (pp. 37-62). London: Kluwer Academic Publishers.

[3] Boekaerts, M., P. R. Pintrich, and M. Zeidner, (Eds.). Handbook of self-regulation (2000). San Diego: Academic Press.

[4] Brown, J. M., W. R. Miller, and L. A. Lawendoski. The Self-regulation Questionnaire. In L. VandeCreek \& T. L. Jackson (Eds.), innovations in clinical practice: A source book, (1999). (Vol. 17, pp. 281-289). Sarasota, FL: Professional Resource Press.

[5] Brown, J. M., Self-regulation and the addictive behaviors. In W .R. Miller and N. Heather (Eds.), Treating addictive, (1998). (2nd ed., pp. 61-74). New York: Plenum Press.

[6] Butler, D. L., and P. H. Winne. Feedback and selfregulated learning: A theoretical synthesis. Review of Education Research, (1995). 65(3), 245-281.

[7] Campbell, C. A., and, C. A. Dahir. Sharing the Vision: The national standards for school counseling programs. Alexandria, VA: American School Counselor Association, (1997).

[8] Chularut, P. and T. K. De Backer, The influence of concept mapping on achievement, self - regulation and self - efficacy in students of English as a second language. Contemporary Education Psychology, (2004). 29, 248 263.

[9] De Shazer, S. Words were originally magic. (1994). New York: Norton.

[10] Deci, E. L., and, R. M. Ryan, A motivational approach to the self: Integration in personality. In $\mathrm{R}$. 
Dienstbier, Nebraska symposium on motivation: Vol. 38. Perspectives on motivation (1991). (pp. 237-288). Lincoln: University of Nebraska Press.

[11] Fisch, R., J. H. Weakland, and L Segal, The tactics of change: Doing therapy briefly. (1982).San Francisco, CA: Jossey-Bass.

[12] Franklin, C., The effectiveness of Solution-Focused Therapy with children in a school setting. Texas and Lake Universities, (2001).

[13] Glasser, W., Choice theory: Kings Beach, CA: Author. (1998).

[14] Harter, S. A model of mastery motivation in children: Individual differences and developmental change. In W. A. Collins, Minnesota. symposium on child psychology: (1981). Vol. 14 (pp. 215-255). Hillsdale, NJ: Erlbaum.

[15] Harter, S., The relationship between perceived competence, affect, and motivational orientation within the classroom: Process and patterns of change: University of Denver Journal of Educational Psychology, (1986). 76, 647-658.

[16] Kanfer, F. H., Self-regulation: Research, issues, and speculation. In C. Neuringer and J.L. Michael (Eds.), Behavior modification in clinical psychology, (1970). (pp. 178-220). New York: Appleton-Century-Crofts.

[17] Locke, E. A., and G. P. Latahm, A theory of goal setting and task performance (1990). Englewood Cliffs, NJ: Prentice-Hall.

[18] Miller, W. R., and J. M. Brown, Self-regulation as a conceptual basis for the prevention and treatment of addictive behaviors. In N. Heather, W. R. Miller \& J. Greeley (Eds.), Self-control and the addictive behaviuors (1991). (pp. 3-79). Sydney: Maxwell Macmillan Publishing Australia.

[19] Molnar, A., S. de Shazer, Solution-focused therapy: Toward the identification of therapeutic tasks. Journal of Marital and Family Therapy, (1987). 13, 349-358.

[20] Nuttin, J., Motivation, planning, and action: A relational theory of behavior dynamics (1980/1984). Leuven and Hillsdale, NJ: Leuven University Press and Erlbaum.

[21] Salomon, G. Television is "easy" and print is "tough": The differential investment of mental effort in learning as a function of perceptions and attributions (1984).

[22] Sanz, M. L., M. D. Ugarte, M. C. Elawar, M. D. Iriarte, and M. T. Sanz. Enhancement of self-regulation, assertiveness, and empathy. Learning and Instruction (2003). 13, 423-439.

[23] Schunk, D. H., and B. J. Zimmerman (Eds.). Selfregulated learning: from teaching to self-reflective practice (1998). New York: Guilford Press.
[24] Some, S. N., Solution-Focused Brief Therapy Group work with At-Risk Junior High School Students: Enhancing the Bottom Line (2004). University of Illinois at Chicago.

[25] White, M., and D. Epston, Narrative means to therapeutic ends (1990). New York: Norton.

[26] Zimmerman, B. J., A social cognitive view of self regulated academic learning. Journal of Educational Psychology (1989). 81, 329-339. 